\title{
Microspheres present comparable efficacy and safety profiles compared with polyvinyl alcohol for bronchial artery embolization treatment in hemoptysis patients
}

\author{
Zhigang Fu ${ }^{1 \dagger}$, Xun $\mathrm{Li}^{2 \dagger}$, Fei Cai ${ }^{1}$, Yinpeng Yuan ${ }^{1}$, Xiaolin Zhang ${ }^{1}$, Jingxia Qin ${ }^{1 *}$ and Yonghui Liang ${ }^{1 *}$
}

\begin{abstract}
Background: The present study aimed to compare the efficacy and safety profiles of microspheres versus (vs.) polyvinyl alcohol (PVA) for bronchial artery embolization (BAE) treatment in patients with hemoptysis.

Methods: Totally, 152 patients with hemoptysis who were about to receive BAE treatment were consecutively enrolled and divided into microspheres group $(N=62)$ and PVA group $(N=90)$. Technical success and clinical success were assessed after BAE procedure, and the hemoptysis-recurrence status, survival status and adverse events were recorded during follow-up.

Results: Technical success rates were both 100\% in microspheres group and PVA group; clinical success rate (96.8\% vs. $100.0 \%, P=0.165), 6$-month $(9.7 \%$ vs. $7.8 \%, P=0.681)$ and 1 -year $(9.7 \%$ vs. $8.9 \%, P=0.869)$ hemoptysis recurrence rate, 6 -month ( $4.8 \%$ vs. $2.2 \%, P=0.374)$ and 1 -year ( $4.8 \%$ vs. $3.3 \%, P=0.639)$ mortality were similar between microspheres group and PVA group. Furthermore, hemoptysis-free survival $(P=0.488)$ and overall survival $(P=0.321)$ were of no difference between two groups. In addition, all adverse events were mild, and there was no difference of adverse events between two groups (all $P>0.05$ ). These data were validated by further multivariate regression analysis.
\end{abstract}

Conclusions: Microspheres present comparable efficacy and safety profiles compared with PVA for the BAE treatment in patients with hemoptysis, providing evidence for embolic agent selection.

Keywords: Hemoptysis, Microspheres, Polyvinyl alcohol, Bronchial artery embolization, Hemoptysis recurrence, Mortality

\section{Background}

Hemoptysis is the expectoration of blood originated from the respiratory tract, and is a clinical manifestation of various pulmonary or tracheobronchial diseases,

\footnotetext{
*Correspondence: jinshan3866@163.com; lianxiesha99@163.com ${ }^{\dagger}$ Zhigang Fu and Xun Li contributed equally to this work ${ }^{1}$ Department of Radiology, Yichang Central People's Hospital, First College of Clinical Medical Science, China Three Gorges University, 183 Yiling Road, Yichang 443003, China
}

Full list of author information is available at the end of the article including bronchiectasis, acute respiratory tract infections, asthma, chronic obstructive pulmonary diseases, and malignancy $[1,2]$. Hemoptysis is regarded as a serious medical emergency, since hemorrhage can flood into airways, leading to the airway obstruction, impairment of ventilation, blood transfusion, and further the occurrence of asphyxia as well as cardiovascular collapse [3]. Even with the existing treatment strategy (including surgery, bronchial artery embolization (BAE), etc.), patients with moderate-to-massive hemoptysis still suffer original author(s) and the source, provide a link to the Creative Commons licence, and indicate if changes were made. The images or other third party material in this article are included in the article's Creative Commons licence, unless indicated otherwise in a credit line to the material. If material is not included in the article's Creative Commons licence and your intended use is not permitted by statutory regulation or exceeds the permitted use, you will need to obtain permission directly from the copyright holder. To view a copy of this licence, visit http://creativecommons.org/licenses/by/4.0/. The Creative Commons Public Domain Dedication waiver (http://creativeco mmons.org/publicdomain/zero/1.0/) applies to the data made available in this article, unless otherwise stated in a credit line to the data. 
from relative high risk of recurrence and morality [4-6]. Hence, development of effective and safe treatment strategies is essential to control bleeding and limit the spread of hemorrhage promptly, further guaranteeing the survival in patients with hemoptysis.

Bronchial artery embolization is an effective and minimally invasive palliative therapeutic approach for the management of hemoptysis, and presents approximately 90\% immediate success rate for short-term hemoptysis control $[7,8]$. The procedures of BAE include the cannulation placement in the targeted bronchial artery and embolization with various embolic agents, and polyvinyl alcohol (PVA) is one of the most extensively used embolic agents [7, 9]. Mechanically, PVA, as a non-biodegradable and biocompatible polymer, is compressed and then introduced into bloodstream, further swelling, and occluding a vessel for the BAE purpose [7]. The efficacy and safety of BAE with PVA in controlling massive hemoptysis has been illustrated, however, PVA still exhibits disadvantage of tendency to aggregate, which may increase the risk of proximal occlusion and long-term hemoptysis recurrence rate [7, 9-12]. Recently, microspheres has gained attention for hemoptysis control as a novel embolic agent in China. Compared with PVA, microspheres present less risk of aggregation, furthermore, it also displays various advantages, such as calibrated size, resistance to aggregate, satisfied elasticity [7, 13-15]. Microspheres has been revealed to be effective and safe in treating hyper-vascular tumor, however, its efficacy and safety has not been explored in hemoptysis yet $[16,17]$.

Therefore, we conducted the present study to compare the efficacy and safety profiles of microspheres versus (vs.) PVA for BAE treatment in patients with hemoptysis, which helped to provide evidence for embolic agent selection.

\section{Methods \\ Patients}

From June 2017 to May 2020, a total of 152 patients with hemoptysis and schedule to receive BAE treatment in our hospital were consecutively enrolled in this study. The inclusion criteria were (1) confirmed as hemoptysis, which was defined as airway bleeding with estimated hemoptysis volume $>20 \mathrm{~mL}$ in each event [18]; (2) age $\geq 18$ years old, and (3) about to receive BAE treatment using polyvinyl alcohol (PVA) or microspheres. The exclusion criteria were (1) history of BAE for hemoptysis, (2) severe abnormality of cardio-pulmonary function or hepatorenal function, (3) contraindication to BAE, and (4) women in pregnancy or lactation. In addition, lung cancer patients with hemoptysis were excluded from this study because their treatments were more complex than others and always need to conduct drug-eluting beads bronchial arterial chemoembolization (DEB-BACE), which can bias the outcome evaluation. The Ethics Committee of our hospital approved this study, and written informed consents were obtained from all patients.

\section{Bronchial artery embolization procedures}

After admission, routine treatments (such as oxygen inhalation, electrocardiogram monitoring and hemostasis drugs) were given to the patients if necessary. Routine examinations (such as computerized tomography (CT) and bronchoscopy) were carried out to confirm etiology. Before BAE, all patients received CT bronchography and angiography (CTBA) to identify offending vessels of hemoptysis as follows: all CTBA procedures were performed in Digital Subtraction Angiography (DSA) room with the use of UNIQ Clarity FD20 (Philips Amsterdam, Netherlands) and nonionic contrast medium (Visipaque, $320 \mathrm{mg} \mathrm{I} / \mathrm{mL}$, GE, Ireland). Under the guidance of DSA, a 5F Cobra (Cordis, USA) catheter was selectively catheterized into the offending vessels at different angles using a modified Seldinger technique. The contrast medium was injected manually to offending vessels, then the direction and angle of the offending vessels in tangent position were fully displayed for next BAE procedures. The BAE procedures were performed using coaxial microcatheter technology under the guidance of DSA. A 2.7 F microcatheter (Terumo, Japan) was super-selectively catheterized into distance of offending vessels under the guidance of micro-guide wire. After the offending vessels were confirmed by DSA once again, the offending vessels were embolized by PVA (300-500 $\mu \mathrm{m}$, Cook Inc., USA) or microspheres (300-500 $\mu \mathrm{m}$, Jiangsu Hengrui Medicine Co. Ltd., China) (shown in Additional file 1: Figure S1).

\section{Technical success and clinical success assessment}

Technical success was defined as the complete embolization of all offending vessels (including bronchial artery and non-bronchial systemic artery) [19]. Clinical success was defined as cessation of hemoptysis or reduction of hemoptysis volume $>50 \%$ during hospitalization after BAE [20].

\section{Follow-up}

At the period of hospitalization, all patients were daily followed up to monitor hemoptysis status and adverse events. After discharging from hospital, regular followup was conducted by telephone or clinical visit. During follow-up, the hemoptysis status, survival status and adverse events were recorded. Hemoptysis-free survival was calculated from the date of BAE to the date of hemoptysis recurrence or death. Overall survival was calculated from the date of BAE to the date of death. 


\section{Statistical analysis}

Statistical analysis was conducted using SPSS 24.0 statistical software (IBM, USA). Figures were plotted using GraphPad Prism 7.01 software (GraphPad lnc., USA). According to the embolic materials, all patients were classified as PVA group $(\mathrm{N}=90)$ and microspheres group $(\mathrm{N}=62)$.

The differences of clinical features between two groups were determined by Student's $t$ test, Chi-square test, Fisher's exact test or Wilcoxon rank sum test. The differences of technical success rate, clinical success rate, hemoptysis recurrence rate, mortality and adverse events occurrence rate between two groups were determined by Chi-square test or Fisher's exact test. Hemoptysis-free survival and overall survival were displayed by Kaplan-Meier curve, and the differences of hemoptysis-free survival and overall survival between two groups were analyzed by log-rank test. Multivariate Cox's proportional hazard regression was used to analyze hemoptysis-free survival and overall survival. $P$ value $<0.05$ was considered as statistically significant.

\section{Results}

\section{Clinical characteristics of patients with hemoptysis}

In microspheres group, the mean age was $61.8 \pm 10.4$ years, and the numbers of females as well as males were $21(33.9 \%)$ and 41 (66.1\%), respectively. As for in PVA group, the mean age was $59.5 \pm 12.9$ years, meanwhile, the numbers of females and males were 38 (42.2\%) and $52(57.8 \%)$ respectively (Table 1$)$. No difference of age, gender, history of smoking, history of drinking, etiology, comorbidities, hemoptysis volume, or offending vessels was observed between microspheres group and PVA group (all $P>0.05$ ). More detailed information about the clinical characteristics were shown in Table 1.

\section{Comparison of success rate, hemoptysis recurrence rate and mortality}

Technical success rates were both $100.0 \%$ in microspheres group and PVA group (Fig. 1A). Meanwhile, clinical success rate was of no difference between microspheres group (96.8\%) and PVA group (100.0\%) $(P=0.165)$ (Fig. 1B). Furthermore, microspheres group presented similar 6 -month $(9.7 \%$ vs. $7.8 \%, P=0.681)$ and 1 -year $(9.7 \%$ vs. $8.9 \%, P=0.869)$ hemoptysis recurrence rate compared to PVA group (Fig. 1C). As for morality, microspheres group exhibited similar 6-month $(4.8 \%$ vs. $2.2 \%, P=0.374)$ and 1 -year $(4.8 \%$ vs. $3.3 \%, P=0.639)$ mortality compared with PVA group (Fig. 1D). These data was validated by further multivariate logistic regression analysis that group (microspheres vs. PVA) was not correlated with hemoptysis recurrence risk $(P=0.669)$
(Table 2$)$ and mortality risk $(P=0.693)$ (Table 3$)$. Meanwhile, only hemoptysis volume $(\mathrm{OR}=2.205, P=0.016)$ and offending vessels of left bronchial artery (vs. bilateral bronchial artery) $(\mathrm{OR}=16.769, P=0.016)$ were independent predictive factors for increased hemoptysis recurrence risk or mortality risk (Tables 2,3 ).

\section{Comparison of hemoptysis-free survival and overall survival}

During the follow-up, the hemoptysis status and survival status were recorded and analyzed, which observed that microspheres group presented no difference of hemoptysis-free survival $(P=0.488)$ (Fig. $2 \mathrm{~A})$ or overall survival $(P=0.321)$ (Fig. 2B) compared with PVA group, which was further validated by multivariate Cox's regression analysis (Tables 4, 5).

\section{Comparison of adverse events}

All the adverse event occurred in microspheres group or PVA group were common and well tolerable (Table 6). In detail, there was no difference of cough/expectoration $(P=0.394)$, fever $(P=0.071)$, chest discomfort $(P=1.000)$, nausea/vomiting $(P=0.514)$, abdominal pain $(P=1.000)$, poor appetite and fatigue $(\mathrm{P}=1.000)$, ecchymosis at the puncture site $(\mathrm{P}=0.408)$, or allergy and dyspnea $(\mathrm{P}=1.000)$ between the two groups (Table 6$)$. More detailed information was shown in Table 6.

\section{Comparison of treatment efficacy and safety profiles in subgroup analysis}

According to the hemoptysis etiology, patients were divided into two subgroups: bronchiectasis patients $(n=130)$ and patients with other etiologies $(n=22)$. In bronchiectasis patients, there was no difference of technical success rate, clinical success rate, hemoptysis recurrence rate, mortality, hemoptysis-free survival, overall survival, or adverse events between microspheres group and PVA group (all $P>0.05$ ) (Fig. 3A-D, Fig. 4A, B, and Additional file 2: Table S1). In patients with other etiologies, there was also no difference of technical success rate, clinical success rate, hemoptysis recurrence rate, mortality, overall survival, or adverse events between microspheres group and PVA group (all $P>0.05$ ), while hemoptysis-free survival was decreased in microspheres group compared with PVA group $(P=0.030)$ (Fig. 3E-H, Fig. 4C, D, and Additional file 2: Table S1).

\section{Discussion}

Polyvinyl alcohol is one of the most widely used embolic agents for BAE as it presents several advantages including high cost-effective, diversity of embolic size depending on offending vessels, easy to handle, durable, etc., meanwhile, the efficacy of BAE with PVA 
Table 1 Clinical features

\begin{tabular}{|c|c|c|c|}
\hline Items & PVA group $(N=90)$ & Microspheres group $(\mathrm{N}=62)$ & $P$ value \\
\hline \multicolumn{4}{|l|}{ Demographic characteristics } \\
\hline Age (years), mean $\pm S D$ & $59.5 \pm 12.9$ & $61.8 \pm 10.4$ & 0.243 \\
\hline Gender, No. (\%) & & & 0.299 \\
\hline Female & $38(42.2)$ & $21(33.9)$ & \\
\hline Male & $52(57.8)$ & $41(66.1)$ & \\
\hline History of smoking, No. (\%) & $34(37.8)$ & $30(48.4)$ & 0.193 \\
\hline History of drinking, No. (\%) & $25(27.8)$ & $20(32.3)$ & 0.552 \\
\hline Etiology, No. (\%) & & & 0.090 \\
\hline Bronchiectasis & $81(90.0)$ & $49(79.1)$ & \\
\hline Tuberculosis & $4(4.5)$ & $4(6.5)$ & \\
\hline NTM infection & $2(2.2)$ & $3(4.8)$ & \\
\hline BA malformation & $0(0.0)$ & $3(4.8)$ & \\
\hline Benign tumor of bronchus & $1(1.1)$ & $0(0.0)$ & \\
\hline Diffuse lesions in bilateral lungs & $1(1.1)$ & $0(0.0)$ & \\
\hline Aortic dissection stent implantation & $1(1.1)$ & $0(0.0)$ & \\
\hline Unknown & $0(0.0)$ & $3(4.8)$ & \\
\hline \multicolumn{4}{|l|}{ Comorbidities, No. (\%) } \\
\hline Hypertension & $14(15.6)$ & $10(16.1)$ & 0.924 \\
\hline COPD & $3(3.3)$ & $4(6.5)$ & 0.367 \\
\hline $\mathrm{CHD}$ & $5(5.6)$ & $0(0.0)$ & 0.080 \\
\hline Chronic bronchitis & $6(6.7)$ & $0(0.0)$ & 0.082 \\
\hline Hepatitis & $4(4.4)$ & $1(1.6)$ & 0.649 \\
\hline Cerebral infarction & $3(3.3)$ & $3(4.8)$ & 0.688 \\
\hline Diabetes mellitus & $1(1.1)$ & $3(4.8)$ & 0.305 \\
\hline Hemoptysis volume, No. (\%) & & & 0.339 \\
\hline$<100 \mathrm{~mL}$ & $63(70.0)$ & $46(74.2)$ & \\
\hline 100-200 mL & $8(8.9)$ & $11(17.7)$ & \\
\hline$>200 \mathrm{~mL}$ & $19(21.1)$ & $5(8.1)$ & \\
\hline Offending vessels, No. (\%) & & & 0.682 \\
\hline Bilateral BA & $59(65.6)$ & $34(54.9)$ & \\
\hline Bilateral BA + others ${ }^{\mathrm{a}}$ & $16(17.8)$ & $16(25.8)$ & \\
\hline Right BA & $9(10.0)$ & $7(11.3)$ & \\
\hline Right $\mathrm{BA}+$ others $^{\mathrm{b}}$ & $2(2.2)$ & $3(4.8)$ & \\
\hline Left BA & $1(1.1)$ & $1(1.6)$ & \\
\hline Left BA + others ${ }^{c}$ & $3(3.3)$ & $1(1.6)$ & \\
\hline
\end{tabular}

Comparison was determined by Student's t test, Chi-square test, Fisher's exact test or Wilcoxon rank sum test

PVA polyvinyl alcohol, SD standard deviation, NTM nontuberculous mycobacterium, BA bronchial artery, COPD chronic obstructive pulmonary disease, CHD coronary heart disease, IPA inferior phrenic artery, ICA intercostal artery, IMA internal mammary artery, TTA thyrocervical trunk artery, CTA costocervical trunk artery

${ }^{\text {a }}$ Others included IPA, ICA, IMA, TTA or CTA

${ }^{b}$ Others included ICA, IMA or TTA

'Others included IMA, IPA or ICA

in controlling hemoptysis has been illustrated by enormous evidence before [7, 9, 12, 14, 21]. For example, a retrospective study indicates that BAE with PVA is utilized in the treatment of 334 hemoptysis patients who presents with the most common etiology of pulmonary tuberculosis with technical success rate of $90.7 \%$, and $6.5 \%$ procedures were repeated within two months due to technical or clinical failures [22]. Furthermore, another study exhibits that the immediate success rate is achieved in $86 \%$ patients, and during the 5-year follow-up, the recurrence rate of hemoptysis was $28 \%$ and mortality was $22 \%$ in patients who receives BAE using PVA for hemoptysis [23]. As for microspheres, they are compressible hydrogel with 
A

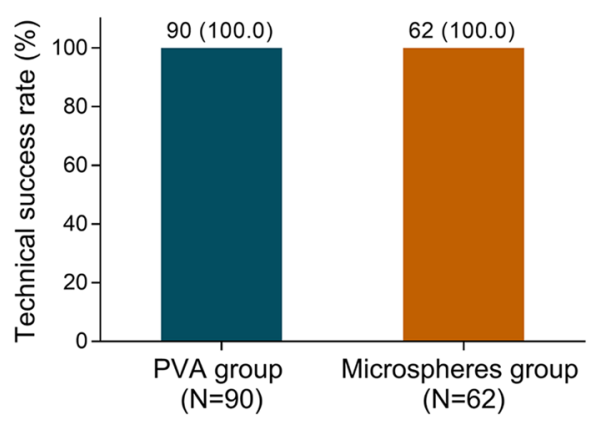

C

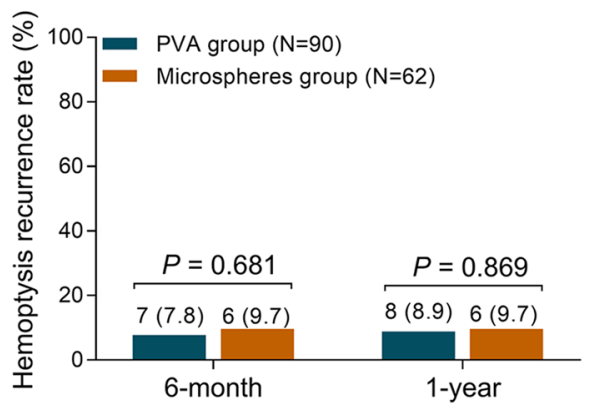

B

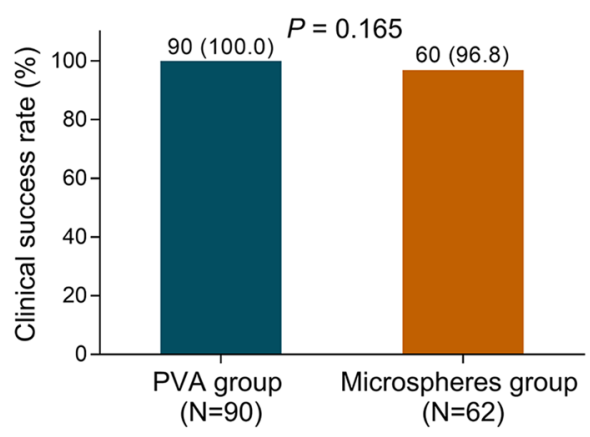

D

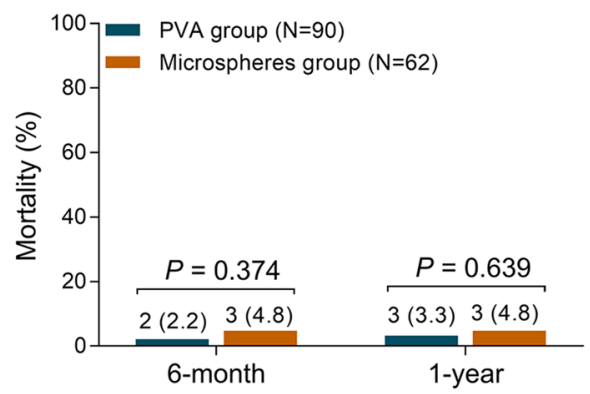

Fig. 1 Technical success, clinical success, hemoptysis recurrence rates and mortality. Comparison of technical success rate (A), clinical success rate (B), hemoptysis recurrence rate $(\mathbf{C})$ and mortality (D) between microspheres group and PVA group. PVA, polyvinyl alcohol

Table 2 Multivariate logistic regression analysis of hemoptysis recurrence risk

\begin{tabular}{|c|c|c|c|c|}
\hline \multirow[t]{3}{*}{ Items } & \multicolumn{4}{|c|}{ Multivariate logistic regression } \\
\hline & \multirow[t]{2}{*}{$P$ value } & \multirow[t]{2}{*}{ OR } & \multicolumn{2}{|l|}{$95 \% \mathrm{Cl}$} \\
\hline & & & Lower & Higher \\
\hline Group (microspheres vs. PVA) & 0.669 & 1.273 & 0.421 & 3.847 \\
\hline Age (>60 years) & 0.481 & 0.679 & 0.232 & 1.990 \\
\hline Male & 0.371 & 1.958 & 0.450 & 8.526 \\
\hline History of smoke & 0.713 & 0.751 & 0.163 & 3.452 \\
\hline History of drink & 0.480 & 1.665 & 0.404 & 6.860 \\
\hline Etiology (bronchiectasis vs. others) & 0.673 & 0.911 & 0.589 & 1.408 \\
\hline Comorbidities (yes vs. no) & 0.698 & 0.803 & 0.265 & 2.437 \\
\hline Hemoptysis volume & 0.016 & 2.205 & 1.160 & 4.194 \\
\hline \multicolumn{5}{|l|}{ Offending vessels } \\
\hline Bilateral BA & Reference & - & - & - \\
\hline Left BA & 0.131 & 4.410 & 0.644 & 30.220 \\
\hline Right BA & 0.205 & 0.246 & 0.028 & 2.154 \\
\hline
\end{tabular}

several advantages including out-standing biocompatibility, resistance to aggregate, satisfied elasticity, and are applied for the embolization in various arteriovenous, including uterine artery, prostatic artery, for
Table 3 Multivariate logistic regression analysis of mortality risk Items

Multivariate logistic regression

$P$ value $\quad$ OR $\quad 95 \% \mathrm{Cl}$

Lower Higher

\begin{tabular}{lllll}
\hline Group (microspheres vs. PVA) & 0.693 & 0.724 & 0.146 & 3.587
\end{tabular}

$\begin{array}{lllll}\text { Age (> 60 years) } & 0.055 & 10.162 & 0.954 & 108.189\end{array}$

$\begin{array}{lllll}\text { Male } & 0.884 & 1.162 & 0.154 & 8.738\end{array}$

$\begin{array}{lllll}\text { History of smoke } & 0.918 & 0.892 & 0.103 & 7.733\end{array}$

$\begin{array}{lllll}\text { History of drink } & 0.724 & 0.691 & 0.089 & 5.391\end{array}$

$\begin{array}{lllll}\text { Etiology (bronchiectasis vs. } & 0.234 & 1.267 & 0.858 & 1.871\end{array}$ others)

$\begin{array}{lllll}\text { Comorbidities (yes vs. no) } & 0.918 & 0.920 & 0.188 & 4.498\end{array}$

$\begin{array}{lllll}\text { Hemoptysis volume } & 0.852 & 0.902 & 0.305 & 2.669\end{array}$

Offending vessels

\begin{tabular}{llrrr} 
Bilateral BA & Reference & \multicolumn{1}{c}{-} & \multicolumn{1}{c}{-} \\
Left BA & 0.016 & 16.769 & 1.702 & 165.199 \\
Right BA & 0.710 & 1.541 & 0.158 & 15.045
\end{tabular}

OR odds ratio, $\mathrm{Cl}$ confidence interval, PVA polyvinyl alcohol, NTM nontuberculous mycobacterium, $B A$ bronchial artery

treatment of several diseases [16, 17, 24, 25]. For example, microspheres exhibits greater ability in improving prostatic volume reduction and peak urinary flow compared with non-spherical PVA particles for prostatic 
A

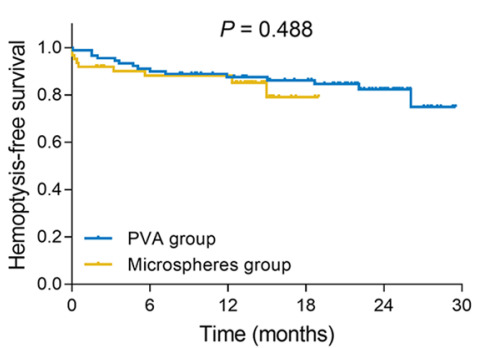

No. at risk

$\begin{array}{lllllll}\text { PVA group } & 90 & 81 & 68 & 58 & 27 & 0 \\ \text { Microspheres group } & 62 & 47 & 30 & 2 & 0 & 0\end{array}$
B

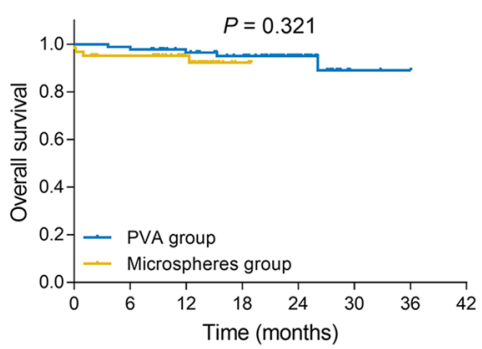

No. at risk

$\begin{array}{llllccccc}\text { PVA group } & 90 & 88 & 74 & 64 & 34 & 2 & 1 & 0 \\ \text { Microspheres group } & 62 & 51 & 33 & 2 & 0 & 0 & 0 & 0\end{array}$

Fig. 2 Survival analysis. Comparison of hemoptysis-free survival (A) and overall survival (B) between microspheres group and PVA group. PVA, polyvinyl alcohol

Table 4 Multivariate Cox's regression analysis of hemoptysis-free survival

\begin{tabular}{|c|c|c|c|c|}
\hline \multirow[t]{3}{*}{ Items } & \multicolumn{4}{|c|}{$\begin{array}{l}\text { Multivariate Cox's proportional } \\
\text { hazard regression }\end{array}$} \\
\hline & \multirow[t]{2}{*}{$P$ value } & \multirow[t]{2}{*}{ HR } & \multicolumn{2}{|l|}{$95 \% \mathrm{Cl}$} \\
\hline & & & Lower & Higher \\
\hline Group (microspheres vs. PVA) & 0.498 & 1.360 & 0.558 & 3.315 \\
\hline Age (>60 years) & 0.418 & 1.434 & 0.600 & 3.431 \\
\hline Male & 0.507 & 1.469 & 0.471 & 4.581 \\
\hline History of smoke & 0.973 & 0.980 & 0.296 & 3.241 \\
\hline History of drink & 0.878 & 0.917 & 0.304 & 2.765 \\
\hline Etiology (bronchiectasis vs. others) & 0.642 & 0.765 & 0.247 & 2.372 \\
\hline Comorbidities (yes vs. no) & 0.840 & 0.914 & 0.384 & 2.179 \\
\hline Hemoptysis volume & 0.145 & 1.454 & 0.879 & 2.405 \\
\hline \multicolumn{5}{|l|}{ Offending vessels } \\
\hline Bilateral BA & Reference & - & - & - \\
\hline Left BA & 0.055 & 3.519 & 0.973 & 12.731 \\
\hline Right BA & 0.457 & 0.569 & 0.129 & 2.507 \\
\hline
\end{tabular}

HR hazards ratio, $\mathrm{Cl}$ confidence interval, PVA polyvinyl alcohol, NTM

nontuberculous mycobacterium, $B A$ bronchial artery

artery embolization treatment in patients with lower urinary tracts symptoms [25]. However, its application in BAE treatment for hemoptysis was limited, therefore we explored the treatment efficacy and safety profiles of BAE with microspheres in hemoptysis patients.

According to previous study, the technical and clinical success rates of BAE using PVA in patients with hemoptysis are reported to be $77-100 \%$ and $85-99 \%$ respectively [7, 14]. In our study, for BAE treatment with PVA, the technical success rate of $100 \%$ observed was within the reported range before, while the clinical success rate of $100 \%$ was a little above the reported rage before, which might be due to relatively small sample size $[7,14]$. In addition, there was no difference
Table 5 Multivariate Cox's regression analysis of overall survival

\begin{tabular}{|c|c|c|c|c|}
\hline \multirow[t]{3}{*}{ Items } & \multicolumn{4}{|c|}{$\begin{array}{l}\text { Multivariate Cox's proportional } \\
\text { hazard regression }\end{array}$} \\
\hline & \multirow[t]{2}{*}{$P$ value } & \multirow[t]{2}{*}{ HR } & \multicolumn{2}{|l|}{$95 \% \mathrm{Cl}$} \\
\hline & & & Lower & Higher \\
\hline Group (microspheres vs. PVA) & 0.570 & 1.533 & 0.350 & 6.713 \\
\hline Age (>60 years) & 0.066 & 7.373 & 0.878 & 61.906 \\
\hline Male & 0.761 & 1.324 & 0.217 & 8.079 \\
\hline History of smoke & 0.912 & 0.890 & 0.111 & 7.128 \\
\hline History of drink & 0.609 & 0.588 & 0.077 & 4.494 \\
\hline Etiology (bronchiectasis vs. others) & 0.825 & 0.782 & 0.088 & 6.927 \\
\hline Comorbidities (yes vs. no) & 0.989 & 0.990 & 0.226 & 4.326 \\
\hline Hemoptysis volume & 0.777 & 0.860 & 0.304 & 2.435 \\
\hline \multicolumn{5}{|l|}{ Offending vessels } \\
\hline Bilateral BA & Reference & - & - & - \\
\hline Left BA & 0.097 & 4.792 & 0.754 & 30.446 \\
\hline Right BA & 0.739 & 1.459 & 0.159 & 13.423 \\
\hline
\end{tabular}

HR hazards ratio, $\mathrm{Cl}$ confidence interval, PVA polyvinyl alcohol, NTM nontuberculous mycobacterium, $B A$ bronchial artery

of clinical success rate (96.8 vs. 100.0\%) between microspheres and PVA groups, which suggested that microspheres presented similar immediate effect on controlling hemoptysis as PVA. The possible reasons might include that (1) The short-term good efficacy of BAE using PVA or microspheres in our study might be attributed to the CTBA evaluation prior to BAE as the regular protocol, which increased the accuracy of identification in the bleeding sources and underlying cause of hemorrhage [3, 4]; (2) Furthermore, the majority of patients presented with mild-to-moderate hemoptysis, thereby decreasing the risk of failure to cannulate the bronchial artery or to facilitate a stable catheter position, which led to technical success rate of both $100 \%$ as well as similar clinical success between two groups 
Table 6 Adverse events in total patients ( $N=152)$

\begin{tabular}{lccc}
\hline Items & PVA group $\mathbf{N}=\mathbf{9 0})$ & Microspheres group (N=62) & $\boldsymbol{P}$ value \\
\hline Cough/expectoration & $29(32.2)$ & $16(25.8)$ & 0.394 \\
Fever & $4(4.4)$ & $8(12.9)$ & 0.071 \\
Chest discomfort & $5(5.6)$ & $3(4.8)$ & 1.000 \\
Nausea/vomiting & $2(2.2)$ & $0(0.0)$ & 0.514 \\
Abdominal pain & $1(1.1)$ & $0(0.0)$ & 1.000 \\
Poor appetite and fatigue & $1(1.1)$ & $0(0.0)$ & 1.000 \\
Ecchymosis at the puncture site & $0(0.0)$ & $0(0.0)$ & 0.408 \\
Allergy and dyspnea & $1(1.1)$ & 0.00 & 1.000 \\
\hline
\end{tabular}

Comparison was determined by Chi-square test or Fisher's exact test

PVA polyvinyl alcohol

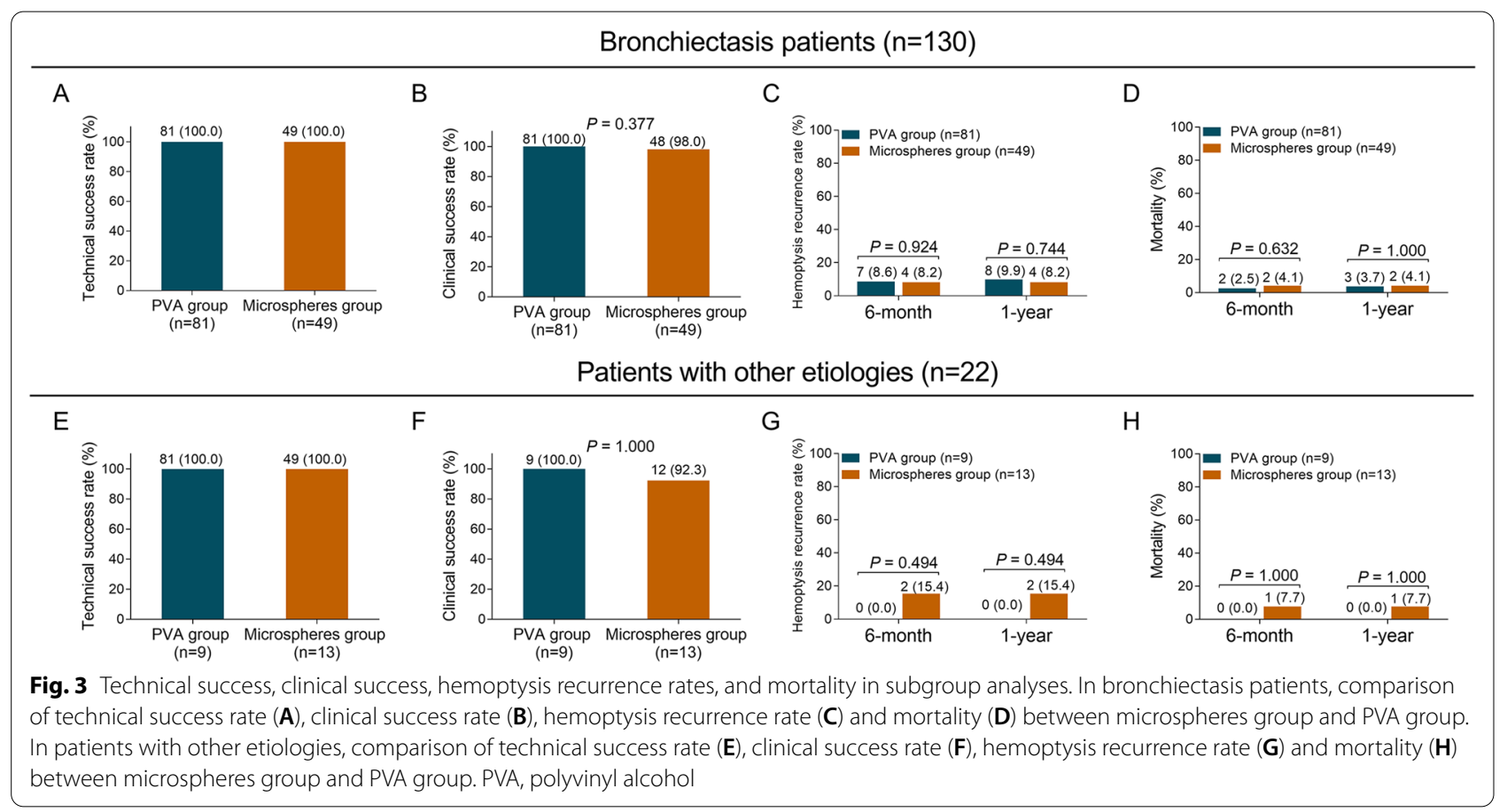

[5, 26]; (3) In addition, considering that microspheres and PVA were made of the same embolic material and of the same size, these two embolic agents therefore displayed similar technical and clinical success rate $[14,27]$. Of note, we found that offending vessels of left bronchial artery rather than right bronchial artery (vs. bilateral bronchial artery) was also an independent predictive factor for increased hemoptysis recurrence risk or mortality risk, which might be explained by that different anatomical structure. Anatomically, left $\mathrm{BA}$ is narrower and longer than right $\mathrm{BA}$, which might increase the failure to identify culprit vessels and therefore enhance hemoptysis recurrence risk and mortality risk [28]. Furthermore, interestingly, we found that hemoptysis volume were independent predictive factors for increased hemoptysis recurrence risk or mortality risk, which might be associated with the difficulty of bleed controlling and unstable hemodynamics, increasing hemoptysis recurrence risk [6].

In our study, 6-month (PVA vs. microspheres: 9.7\% vs. $7.8 \%$ ) and 1-year (PVA vs. microspheres: $9.7 \%$ vs. 8.9\%) hemoptysis recurrence rates were similar between BAE using microspheres and BAE using PVA. The incidences of hemoptysis recurrence in our study were a little reduced compared with the data in previous studies, which reported that the hemoptysis-recurrence rate after BAE was estimated to be $10-29 \%[7,26]$. The possible explanations might include (1) the relatively short 


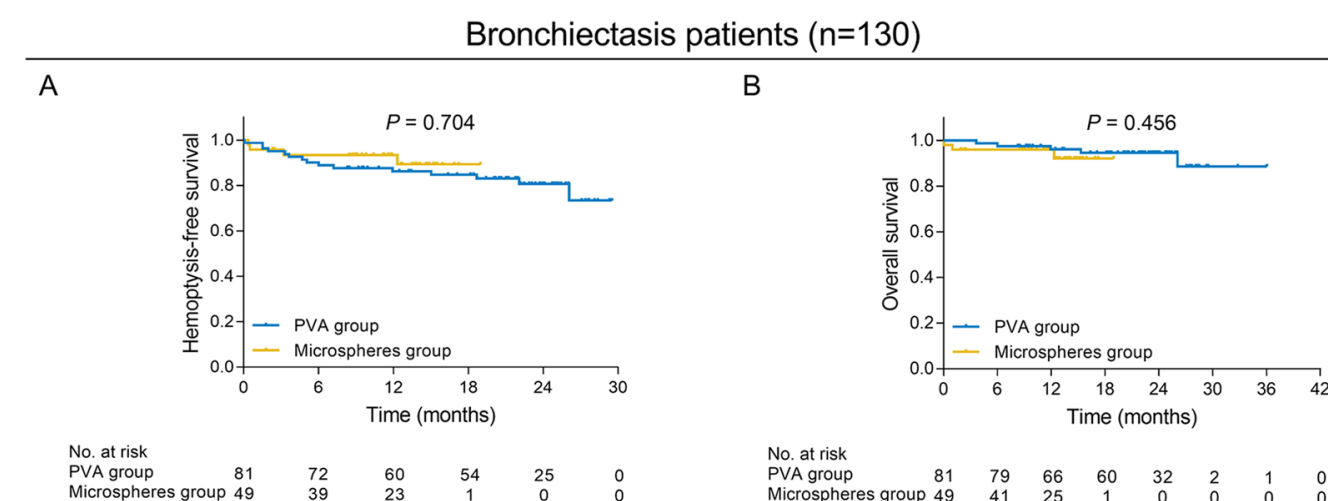

Patients with other etiologies $(n=22)$

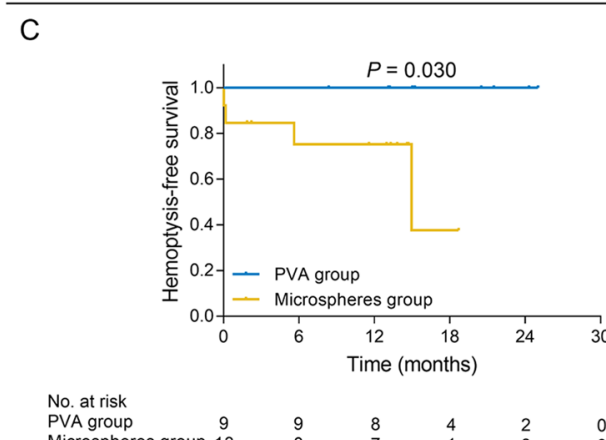

D

$\begin{array}{lcccccc}\text { PVA group } & 9 & 9 & 8 & 4 & 2 & 0 \\ \text { Microspheres group } 13 & 8 & 7 & 1 & 0\end{array}$

\section{No. at risk}

$\begin{array}{lcccccc}\text { PVA group } & 9 & 9 & 8 & 4 & 2 & 0 \\ \text { Microspheres group } & 13 & 10 & 8 & 1 & 0 & 0\end{array}$

Fig. 4 Survival in subgroup analyses. In bronchiectasis patients, comparison of hemoptysis-free survival (A) and overall survival (B) between microspheres group and PVA group. In patients with other etiologies, comparison of hemoptysis-free survival (C) and overall survival (D) between microspheres group and PVA group. PVA, polyvinyl alcohol

follow-up in our study, (2) the exclusion of the patients with lung cancer, which was correlated with a great high likelihood of bleeding recurrence [29, 30]. Furthermore, according to the previous evidence, PVA presented increased aggregation compared with microspheres, which might lead to premature embolization proximal to the intended vascular level, further contributing to higher risk of long-term hemoptysis recurrence rate [14]. However, we did not observe the increased hemoptysis recurrence rate in PVA compared with microspheres in our study, which might be due to relatively small sample size and insufficient follow-up. Furthermore, based on existing evidence, the main causes of recurrent hemoptysis consisted of incomplete embolization of the vessels, revascularization of the collateral circulation or progression of the underlying pulmonary disease rather than embolic agents used, which might explain that microspheres displayed similar hemoptysis recurrence rates as PVA [14]. In addition, 6-month and 1-year mortality were also similar between PVA and microspheres in hemoptysis patients. The possible reasons include that (1) considering the prior data, PVA presented similar hemoptysis recurrence rate compared to microspheres, thereby contributing to the similar hemoptysis-related mortality between PVA and microspheres as well; (2) Based on the previous study, the primary cause for mortality after the treatment of BAE was the underlying progression of disease, and meanwhile considering the similar mechanism and short-term treatment efficacy between PVA and microspheres, therefore, BAE using PVA presented similar mortality to BAE using microspheres. In addition, no correlation of embolic agents with hemoptysis recurrence, mortality, hemoptysis-free survival and overall survival was further validated in multivariate logistic regression analysis. Moreover, further subgroup analysis revealed that there was no difference of clinical success rate, hemoptysis recurrence rate, morality, overall survival between PVA and microspheres in subgroup of bronchiectasis patients and patients with other etiologies, while hemoptysis-free survival was increased in patients receiving BAE using PVA compared with patients receiving BAE using microspheres in subgroup of patients with other etiologies, which might be attributed to the relatively small sample size.

As for adverse events, there was no difference of adverse event incidence between BAE using PVA and 
BAE using microspheres, and main adverse events were relatively minor and well-tolerated (including cough/expectoration, fever, chest discomfort, nausea/ vomiting, abdominal pain, poor appetite and fatigue, ecchymosis at the puncture site, and allergy as well as dyspnea). Theses minor adverse events were common in BAE procedures, which was in accordance with the observation in previous studies [31]. Possible explanations for the lack of major complications included that (1) The size of PVA and microspheres were both 300$500 \mu \mathrm{m}$ in diameter, which could fit with pulmonary artery and avoid distal occlusion of normal peripheral branches, decreasing the possibility of some major complications (such as: esophageal, bronchial, pulmonary artery necrosis) caused by ischemia [7]; (2) Furthermore, with the help of routine CTBA evaluation before BAE combined with angiography during procedure, the spinal collaterals were clearly identified, which decreased the possibility of off-target embolization of the spinal artery as well as the risk of BAE-related neurologic complications [3]. Furthermore, considering the comparative cost-efficacy, microsphere (CNY1600/ bottle) was cheaper than PVA (CNY1710/bottle), it was more reasonable to use microsphere rather than PVA.

Our study filled the gap to assess the efficacy and safety profile of Chinese local microspheres and further to compare its efficacy and safety with frequentlyused PVA for BAE treatment in hemoptysis patients, which observed that microspheres presented similar efficacy on controlling hemoptysis and safety profile as PVA. Meanwhile, considering the more favorable cost of microspheres compared with PVA, the evidence suggested that microsphere might be an alternative option to PVA in BAE treatment. However, the present study still existed some limitations including (1) the sample size was relatively small in our study, which might lead to less statistical validation, more patients from multiple centers were needed for validation; (2) Longer follow-up was needed to observe the adverse events in hemoptysis patients underwent BAE; (3) The majority of patients included were with mild-to-moderate hemoptysis, therefore, more studies were necessary for extending our results in the treatment of massive hemoptysis [5, 26]; (4) As this present study was an observational study, the patients enrolled in our study were not randomized into two groups, which might contribute to selection bias and confounding factors in present study.

In conclusion, BAE with microspheres presents comparable efficacy and safety profiles compared with BAE with PVA for the treatment of hemoptysis, therefore, microspheres may serve as an alternative embolic agent in hemoptysis management.

\section{Supplementary Information}

The online version contains supplementary material available at https://doi. org/10.1186/s12967-021-02947-7.

Additional file1. Technical success, clinical success, hemoptysis recurrence rates and mortality

Additional file2: Table S1. Subgroup analysis of adverse events.

\section{Acknowledgements}

Not applicable.

\section{Authors' contributions}

$Z F, X L$ made substantial contributions to the design of the present study. Data acquisition and interpretation was performed by $Z F, X L, F C, Y Y, X Z$, JQ and $Y L$.

All authors agree to be accountable for all aspects of the work in ensuring that questions related to the accuracy or integrity of the work are appropriately

investigated and resolved. All authors read and approved the final manuscript.

\section{Funding}

Not applicable.

Availability of data and materials

Data sharing is not applicable to this article as no datasets were generated or analysed during the current study.

\section{Declarations}

Ethics approval and consent to participate

The Ethics Committee of our hospital approved this study, and written informed consents were obtained from all patients.

\section{Consent for publication}

Not applicable.

\section{Competing interests}

The authors declare that they have no competing interests.

\section{Author details}

${ }^{1}$ Department of Radiology, Yichang Central People's Hospital, First College of Clinical Medical Science, China Three Gorges University, 183 Yiling Road, Yichang 443003, China. ' Department of Radiology, People's Hospital of Dangyang country, Dangyang 444100, China.

Received: 2 April 2021 Accepted: 17 June 2021

Published online: 11 October 2021

\section{References}

1. Kang MJ, Kim JH, Kim YK, Lee HJ, Shin KM, Kim Jl, Lee HJ, Do KH, Yong HS, Choi SJ, et al. 2018 Korean clinical imaging guideline for hemoptysis. Korean J Radiol. 2018;19:866-71.

2. Earwood JS, Thompson TD. Hemoptysis: evaluation and management. Am Fam Physician. 2015;91:243-9.

3. Davidson K, Shojaee S. Managing massive hemoptysis. Chest. 2020;157:77-88.

4. Sakr L, Dutau H. Massive hemoptysis: an update on the role of bronchoscopy in diagnosis and management. Respiration. 2010;80:38-58.

5. Lee MK, Kim SH, Yong SJ, Shin KC, Kim HS, Yu TS, Choi EH, Lee WY. Moderate hemoptysis: recurrent hemoptysis and mortality according to bronchial artery embolization. Clin Respir J. 2015;9:53-64.

6. Johnson JL. Manifestations of hemoptysis: how to manage minor, moderate, and massive bleeding. Postgrad Med. 2002;112(4):101-13.

7. Yoon W. Embolic agents used for bronchial artery embolisation in massive haemoptysis. Expert Opin Pharmacother. 2004;5:361-7. 
8. Dorji K, Hongsakul K, Jutidamrongphan W, Oofuvong M, Geater S. Bronchial artery embolization in life-threatening hemoptysis: outcome and predictive factors. J Belg Soc Radiol. 2021;105:5.

9. Cantu JA, Safdar Z. Hemoptysis requiring bronchial artery embolization in pulmonary arterial hypertension. South Med J. 2010;103:887-91.

10. Lu LS, Liu YM, Ma QY, Zhou ML, Gong QE, Jia SY, Ren YX. Bronchial artery embolization with polyvinyl alcohol foam and gelatinum sponge for serious hemoptysis. J South Med Univ. 2005;25:422-3.

11. Hahn S, Kim YJ, Kwon W, Cha SW, Lee WY. Comparison of the effectiveness of embolic agents for bronchial artery embolization: gelfoam versus polyvinyl alcohol. Korean J Radiol. 2010;11:542-6.

12. Ozkok A, Ucar AS, Akpinar TS, Okumus G, Kiyan E, Arseven O. Multiple systemic infarctions as a complication of bronchial artery embolization with polyvinyl alcohol: a case report. J Clin Med Res. 2011;3:275-7.

13. Kucukay F, Topcuoglu OM, Alpar A, Altay CM, Kucukay MB, Ozbulbul NI. Bronchial artery embolization with large sized (700-900 microm) tris-acryl microspheres (embosphere) for massive hemoptysis: long-term results (clinical research). Cardiovasc Intervent Radiol. 2018:41:225-30.

14. Panda A, Bhalla AS, Goyal A. Bronchial artery embolization in hemoptysis: a systematic review. Diagn Interv Radiol. 2017:23:307-17.

15. CalliSpheres embolic microspheres, 8spheres embolic microspheres. https://www.accessdata.fda.gov/cdrh_docs/pdf17/K173871.pdf. Accessed 23 July 2021.

16. Cun J, Jiang Y, Zong X, Wan C, Fan H, Cai S. Transarterial chemoembolization by using callispheres drug-eluting beads combined with 8Spheres microsphere for the treatment of advanced hepatocellular carcinoma: study on its short-term efficacy and safety. J Int Radiol. 2019;28:237-41.

17. Guo LY, Liu XX, Li ZY, Qin XY, Fan ZY, Li ZZ, Guan HT, Song L, Zou YH, Fan TY. Preparation and evaluation of blank and doxorubicin loaded poly (acrylic acid) microspheres for embolization. Health Sci. 2018;50:1070-7.

18. Ishikawa H, Hara M, Ryuge M, Takafuji J, Youmoto M, Akira M, Nagasaka Y, Kabata D, Yamamoto K, Shintani A. Efficacy and safety of super selective bronchial artery coil embolisation for haemoptysis: a single-centre retrospective observational study. BMJ Op. 2017;7:e014805.

19. Woo S, Yoon CJ, Chung JW, Kang SG, Jae HJ, Kim HC, Seong NJ, Kim YJ, Woo YN. Bronchial artery embolization to control hemoptysis: comparison of N-butyl-2-cyanoacrylate and polyvinyl alcohol particles. Radiology. 2013:269:594-602.

20. Fu Z, Guo J, Huang Q, Li D, Zhou H, Tan C, Sun P, Qin J, Xie Y, Zhang X, Chen $\mathrm{H}$. Efficacy and safety of drug-eluting beads bronchial arterial chemoembolization in treating patients with lung cancer who were complicated with hemoptysis. Cancer Biother Radiopharm. 2020. https:// doi.org/10.1089/cbr.2020.3954.

21. Yu-Tang Goh P, Lin M, Teo N, Wong DE. Embolization for hemoptysis: a six-year review. Cardiovasc Intervent Radiol. 2002;25:17-25.

22. Bhalla A, Kandasamy D, Veedu P, Mohan A, Gamanagatti S. A retrospective analysis of 334 cases of hemoptysis treated by bronchial artery embolization. Oman Med J. 2015;30:119-28.

23. Shin BS, Jeon GS, Lee SA, Park MH. Bronchial artery embolisation for the management of haemoptysis in patients with pulmonary tuberculosis. Int J Tuberc Lung Dis. 2011;15:1093-8.

24. Tellapuri S, Park HS, Kalva SP. Pulmonary arteriovenous malformations. Int J Cardiovasc Imaging. 2019;35:1421-8.

25. Hwang JH, Park SW, Chang IS, Jung SI, Jeon HJ, Lho YS, Kim HG, Paick $\mathrm{SH}$, Park HK. Comparison of nonspherical polyvinyl alcohol particles and microspheres for prostatic arterial embolization in patients with benign prostatic hyperplasia. Biomed Res Int. 2017;2017:8732351.

26. Gavelli F, Patrucco F, Statti G, Balbo PE. Mild-to-moderate hemoptysis: a diagnostic and clinical challenge. Minerva Med. 2018;109:239-47.

27. Swanson KL, Johnson CM, Prakash UB, McKusick MA, Andrews JC, Stanson AW. Bronchial artery embolization : experience with 54 patients. Chest. 2002;121:789-95.

28. Zhang J, Zheng L, Zhao T, Huang S, Hu W. A retrospective analysis of risk factors in recurrent hemoptysis patients with non-bronchial systematic artery feeding. Ann Transl Med. 2020;8:1593.

29. Chen J, Chen LA, Liang ZX, Li CS, Tian Q, Yang Z, Jiang YW, She DY Immediate and long-term results of bronchial artery embolization for hemoptysis due to benign versus malignant pulmonary diseases. Am J Med Sci. 2014;348:204-9.

30. Fruchter O, Schneer S, Rusanov V, Belenky A, Kramer MR. Bronchial artery embolization for massive hemoptysis: Iong-term follow-up. Asian Cardiovasc Thorac Ann. 2015;23:55-60.

31. Liu H, Zhang D, Zhang F, Yin J. Immediate and long-term outcomes of endovascular treatment for massive hemoptysis. Int Angiol. 2016;35:469-76.

\section{Publisher's Note}

Springer Nature remains neutral with regard to jurisdictional claims in published maps and institutional affiliations.
Ready to submit your research? Choose BMC and benefit from:

- fast, convenient online submission

- thorough peer review by experienced researchers in your field

- rapid publication on acceptance

- support for research data, including large and complex data types

- gold Open Access which fosters wider collaboration and increased citations

- maximum visibility for your research: over 100M website views per year

At BMC, research is always in progress.

Learn more biomedcentral.com/submissions 